\title{
Revamp of existing lab-scale electrolytic cell design for electrolyzed water study in cleaning application
}

\author{
${ }^{1}$ Sulaiman, N.S., ${ }^{1}$ Khalid, N.I., ${ }^{1}$ Fauzi, E.M.H., ${ }^{1,2 *}$ Ab Aziz, N., ${ }^{3}$ Yusof, N.A., ${ }^{4}$ Sobri, S. and \\ ${ }^{1}$ Hasnan, N.Z.N. \\ ${ }^{1}$ Department of Process and Food Engineering, Faculty of Engineering, Universiti Putra Malaysia, 43400 \\ Serdang, Selangor, Malaysia. \\ ${ }^{2}$ Halal Products Research Institute, University Putra Malaysia, 43300 UPM Serdang, Selangor, Malaysia. \\ ${ }^{3}$ Department of Chemistry, Faculty of Science, Universiti Putra Malaysia, 43400 Serdang, Selangor, \\ Malaysia. \\ ${ }^{4}$ Department of Chemical and Environmental Engineering, Faculty of Engineering, Universiti Putra \\ Malaysia, 43400, UPM Serdang, Selangor, Malaysia.
}

\begin{abstract}
Article history:
Received: 7 May 2020

Received in revised form: 29

September 2020

Accepted: 29 December 2020

Available Online: 31

December 2020
\end{abstract}

\section{Keywords:}

Electrolysis,

Green cleaner,

Corrosion,

Cleaning,

Food industries

DOI:

https://doi.org/10.26656/fr.2017.4(S6).040

\begin{abstract}
The lab-scale electrolytic cell was designed to produce acidic and alkaline electrolyzed water for cleaning study. Electrolyzed water (EW) was produced by electrolysis of a dilute sodium chloride solution. The generation of free chlorine, $\mathrm{pH}$ and oxidation-reduction potential from the electrolysis process by the electrolytic cell were far from the expected value. Thus, the lab-scale electrolytic cell was revamped by using the acrylic slot to hold the electrode plate and a membrane holder without metal screws. This revamp work is to reduce the resistance for current flow with the aim to increase the value of chemical properties $(\mathrm{pH}$, oxidation-reduction potential, free chlorine) for acidic and alkaline electrolyzed water. Findings have shown that the current was increased from $0.013 \mathrm{~A}$ to $2.5 \mathrm{~A}$ after the revamp process. As a result of the revamp, the value of $\mathrm{pH}$, oxidationreduction potential and free chlorine for acidic electrolyzed water was increased by 1.7 times, 2.7 times, and 20 times higher than previous results respectively. While for alkaline electrolyzed water, the value of $\mathrm{pH}$ and oxidation-reduction potential was increased by 1.4 times and 6.2 times higher than previous results respectively.
\end{abstract}

\section{Introduction}

The lab-scale electrolytic cell was designed with two chambers separated with a membrane to allow the reactions of ions exchange (Hsu et al., 2015; Khalid et al., 2018). The unit was used to produce acidic and alkaline electrolyzed water at anode and cathode electrodes, respectively. By passing an electric current Hricova et al. (2008) discovered that acidic electrolyzed water (AcEW) is generated when negatively charged ions move to anode and become oxygen gas $\left(\mathrm{O}_{2}\right)$, chlorine gas $\left(\mathrm{Cl}_{2}\right)$, hypochlorite ion (-OCL), hypochlorous acid (HOCL), and hydrochloric acid (HCL). Meanwhile, alkaline electrolyzed water (AlEW) is generated when positively charged ions move to the cathode and become hydrogen gas $\left(\mathrm{H}_{2}\right)$ and sodium hydroxide $(\mathrm{NaOH})$. AcEW has reported having an antimicrobial effect on various microbes and high chlorine concentration was the main contributor (Koseki and Itoh, 2001; Park et al., 2009). While AlEW is compatible to be an alkaline wash use for cleaning application (Khalid et al., 2018). EW with a $\mathrm{pH}$ of 2.56.0 resulted in an approximately 5-log reduction of Listeria monocytogenes (Rahman et al., 2010). Stevenson et al. (2016) reported that ORP value higher than $850 \mathrm{mV}$ caused an efficient inactivation of $E$. coli O157:H7. According to Park et al. (2004), complete inactivation of Listeria monocytogenes and $E$. coli O157:H7 was performed with chlorine levels above 1.0 $\mathrm{mg} / \mathrm{l}$. Therefore, appropriate quality of electrolyzed water is needed for cleaning application in food industries. However, the chlorine concentration in AcEW obtained by using the lab-scale electrolytic cell was too low to efficiently act as a disinfecting agent.

The objective of the study is to improve the design of the electrolytic cell which focused on current generation and good chemical properties ( $\mathrm{pH}$, oxidationreduction potential and chlorine concentration) of acidic and alkaline electrolyzed water. 


\section{Materials and methods}

\subsection{Revamp design methodology}

The revamp study has been conducted for the following aspect:

a. Selection of electrode plate at anode and cathode

b. Position of electrode

c. Modification of membrane set-up

d. Modification of assemble DC power

\subsection{Analytical measurement of electrolyzed water}

Free chlorine was measured by Photometer PF-3 (Macherey-Nagel, Germany) after the electrolysis process. pH was measured by AP85 Portable Waterproof $\mathrm{pH} /$ conductivity meter (Fisher Scientific, USA). Oxidation-reduction potential (ORP) was measured by PT-380 Hand-held pH/ORP/Temperature Meter with redox electrode (Boeco, Germany).

\section{Results and discussion}

Findings of this work have eliminated corrosion problems due to the previous electrode arrangement, where Titanium electrode was placed at the anode. To reduce the galvanic corrosion rates, the more active metal is placed at the anode and more noble metal at the cathode (Shi et al., 2012). In galvanic series, smaller electrode potential difference will cause less corrosion thus stainless steel is chosen since it is relatively close to Titanium. Thus, Titanium which is more noble metal is placed at the cathode and Stainless Steel is placed at anode after revamp. Electrode gap also plays an important role where the smaller the gap between electrodes, the amount of current flow increased and generated more chlorine concentration (Hsu et al., 2017). The gap between both electrodes has decreased to $1.2 \mathrm{~cm}$ and faced towards each other which significantly improved the ions exchange between electrodes.

From Figure 1, the DC power supply to the electrolytic cell before revamping used alligator clip and connected to copper hooks that held the electrodes. These causes high resistance value, thus lowering the current flow. Therefore, the electrode plate was connected directly to the DC power supply in this revamp work to increase the current flow. Furthermore, the presence of metal bolts to attach the membrane in the previous electrolytic cell has caused corrosion where electrolyzed water appeared in brownish solution. Thus, bolts were removed, and an acrylic slot was replaced to hold the membrane.

Table 1. Chemical properties of acidic and alkaline EW before revamp, at $0.5 \% \mathrm{NaCl}$ concentration and 10 mins of electrolysis time.

\begin{tabular}{cccc}
\hline Type of EW & Voltage & Current (A) & $\mathrm{pH}$ \\
\hline AcEW & 16 & 0.013 & 4.66 \\
AlEW & & & 8.5 \\
\hline
\end{tabular}

Table 2. Chemical properties of acidic and alkaline EW after revamp, at $0.5 \% \mathrm{NaCl}$ concentration and $10 \mathrm{mins}$ of electrolysis time.

\begin{tabular}{cccc}
\hline Type of EW & Voltage & Current (A) & $\mathrm{pH}$ \\
\hline AcEW & 15 & 2.50 & 2.77 \\
AlEW & & & 11.56 \\
\hline
\end{tabular}

The chemical properties $(\mathrm{pH}$, oxidation-reduction potential and chlorine concentration) of acidic and alkaline electrolyzed water before and after the revamp of the electrolytic cell are presented in Table 1 and Table 2 respectively. The comparison was constructed by selecting the nearest operating condition to produce acidic and alkaline electrolyzed water. It can be clearly seen from the data that after the revamp, the current has

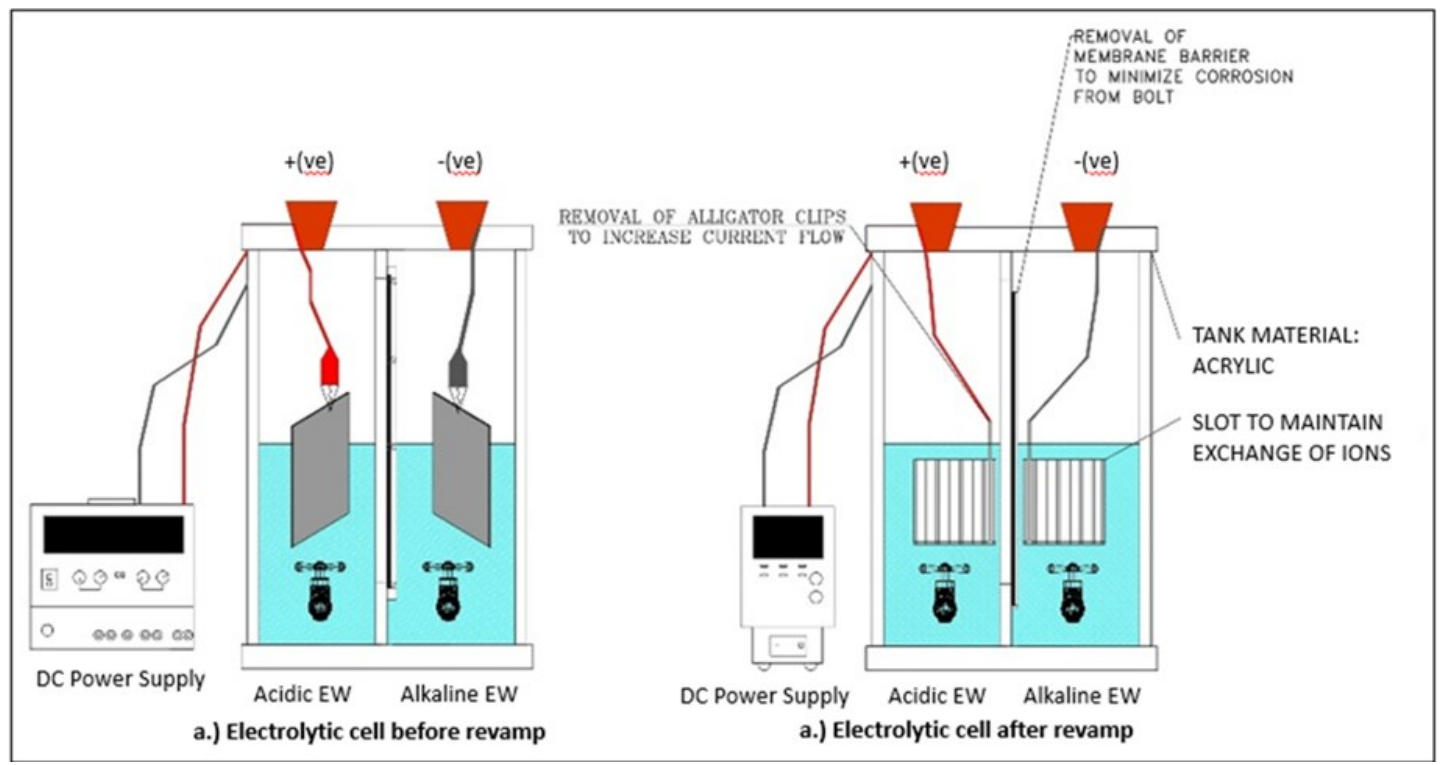

Figure 1. Schematic diagram of lab-scale electrolytic cell in Department of Process and Food Engineering, Faculty of Engineering, Universiti Putra Malaysia a.) before and b.) after the revamp. 
increased from $0.013 \mathrm{~A}$ to $2.50 \mathrm{~A}$. This leads to an increase in $\mathrm{pH}$, oxidation-reduction potential, and free chlorine concentration for both electrolyzed water. This was proved by Rahman et al. (2012), where the values of chlorine concentration, $\mathrm{pH}$ and oxidation-reduction potential increased as the current is increased. Before revamp, the chemical properties of electrolyzed water were low even though the value of voltage is higher compared to the value after revamped. This may be due to the previous set up that caused the low current flow to the electrodes.

\section{Conclusion}

This work has shown convincing results. The current increased by 192 times higher than previous value by considering various aspect on the lab-scale electrolytic cell. The new design is indeed possible to increase the amperage and improved the chemical properties $(\mathrm{pH}$, oxidation-reduction potential and chlorine concentration) for both electrolyzed water. Additionally, the selection of stainless steel 316 as anode could suppress corrosion from occurred due to its excellent corrosion resistance. Thus, this work has proved that the electrolytic cell is competent for producing EW that suits cleaning application in food industries. Electrolyzed water obtained from this study will be used for future study in cleaning application on food contact surfaces.

\section{Acknowledgement}

The author would like to thank Universiti Putra Malaysia for financial support (9658400).

\section{References}

Hricova, D., Stephan, R. and Zweifel, C. (2008). Electrolyzed Water and Its Application in the Food Industry. Journal of Food Protection, 71(9), 1934 1947. https://doi.org/10.4315/0362-028X-71.9.1934

Hsu, G.S.W., Hsia, C.W. and Hsu, S.Y. (2015). Effects of electrode settings on chlorine generation efficiency of electrolyzing seawater. Journal of Food and Drug Analysis, 23(4), 729-734. https:// doi.org/10.1016/j.jfda.2015.06.007

Hsu, G.S.W., Lu, Y.F. and Hsu, S.Y. (2017). Effects of electrolysis time and electric potential on chlorine generation of electrolyzed deep ocean water. Journal of Food and Drug Analysis, 25(4), 759-765. https:// doi.org/10.1016/j.jfda.2016.07.001

Khalid, N.I., Sulaiman, S., Ab Aziz, N., Taip, F.S., Sobri, S. and Nor-Khaizura, M.A.R. (2018). Electrolyzed water as a green cleaner: chemical and physical characterization at different electrolysing parameters. Food Research, 2(6), 512-519. https:// doi.org/10.26656/fr.2017.2(6).107

Park, H., Hung, Y.C. and Chung, D. (2004). Effects of chlorine and $\mathrm{pH}$ on efficacy of electrolyzed water for inactivating Escherichia coli O157:H7 and Listeria monocytogenes. International Journal of Food Microbiology, 91(1), 13-18. https://doi.org/10.1016/ S0168-1605(03)00334-9

Rahman, S.M.E., Ding, T. and Oh, D.H. (2010). Inactivation effect of newly developed low concentration electrolyzed water and other sanitizers against microorganisms on spinach. Food Control, 21(10), 1383-1387. https://doi.org/10.1016/ j.foodcont.2010.03.011

Rahman, S.M.E., Park, J.H., Wang, J. and Oh, D.H. (2012). Stability of low concentration electrolyzed water and its sanitization potential against foodborne pathogens. Journal of Food Engineering, 113(4), $548-553$.

https://doi.org/10.1016/

j.jfoodeng.2012.07.011

Shi, X., Rock, S.E., Turk, M.C. and Roy, D. (2012). Minimizing the effects of galvanic corrosion during chemical mechanical planarization of aluminum in moderately acidic slurry solutions. Materials Chemistry and Physics, 136(2-3), 1027-1037. https://doi.org/10.1016/j.matchemphys.2012.08.044

Stevenson, S.M.L., Cook, S.R., Bach, S.J. and Mcallister, T.A. (2016). Effects of water source, dilution, storage and bacterial and fecal loads on the efficacy of electrolyzed oxidizing water for the control of Escherichia coli O157:H7. Journal of Food Protection, 67(7), 1377-1383. https:// doi.org/10.4315/0362-028X-67.7.1377 